\title{
Genetic diversity and structure of Oriental and European beech populations from Iran and Eu- rope
}

\author{
Mahboobeh Mohebi Bijarpasi"\#, Markus Müller, ${ }^{2 \#}$ Oliver Gailing ${ }^{2 *}$
}

\author{
${ }^{1}$ University of Guilan, Faculty of Natural Science, Sowme Sara, P.O.Box 1144, Guilan, Iran \\ ${ }^{2}$ University of Goettingen, Faculty for Forest Sciences and Forest Ecology, Forest Genetics and Forest Tree Breeding. \\ Büsgenweg 2, 37077 Göttingen, Germany \\ "these authors contributed equally to this work
}

*Corresponding author, e-mail: ogailin@gwdg.de

\begin{abstract}
Genetic variation is a major component of plant development and adaptation, and recent studies have shown that genetic variation among plant species can have important ecological effects. Oriental beech (Fagus orientalis Lipsky) is a dominant tree species in the Hyrcanian forests, where it occupies approximately $18 \%$ of the forested area. In this study, nine expressed sequence tag simple sequence repeat (EST-SSR) markers were used to determine the genetic diversity and structure of Iranian Oriental beech populations growing at different altitudes. We further compared the genetic structures of the Iranian populations to a F. orientalis and a Fagus sylvatica L. population from the hybrid zone of the two taxa in southeast Europe, and to a F. sylvatica population from central Europe. All populations showed a high genetic diversity, which was similar to other $F$. orientalis and F. sylvatica populations from Europe. The genetic differentiation among Iranian beech populations was very low. In contrast, distinct genetic differentiation was found between the Iranian populations and the analyzed European populations (F. orientalis and F. sylvatica). One EST-SSR was identified to differentiate $\left(G_{S T}: 0.503\right)$ between $F$. orientalis and $F$. sylvatica with very pronounced allele frequency differences between taxa. Specifically, the Fagus sylvatica characteristic allele 189 was almost absent from all Iranian populations and present in low frequencies in F. orientalis populations from other regions. This study helps to extend the knowledge of genetic diversity and genetic structure of Iranian Oriental beech populations. It further gives insights into the genetic differentiation between F. orientalis populations from the center and the edge of the species' distribution range as well as between Oriental and European beech.
\end{abstract}

Keywords: : Genetic diversity, genetic structure, microsatellite, Fagaceae, Fagus orientalis, Fagus sylvatica, Hyrcanian forest

\section{Introduction}

Oriental beech (Fagus orientalis Lipsky) is one of the most important tree species in Iran distributed throughout the Caspian Sea provinces and along the northern slopes of Alborz Mountains. Pure and mixed Iranian beech forests are the richest and the most beautiful forests of Iran containing trees up to $50 \mathrm{~m}$ height and $2 \mathrm{~m}$ diameter (Salehi Shanjani et al. 2004). It is a dominant tree species in the Hyrcanian forests and occupies approximately $18 \%$ of the region's forests, extending over a wide altitudinal range from 700 to $2200 \mathrm{~m}$ above the Caspian Sea, producing more than $35 \%$ of the total wood (Ahmadi et al. 2009, Bayramzadeh et al. 2012). Few population genetic studies have been conducted yet on Oriental beech in Iran (e.g., Salehi Shanjani et al. 2002, Salehi Shanjani et al. 2004, Salehi Shanjani et al. 2010). For example, intraspecific variation and geographic patterns of $14 \mathrm{~F}$. orientalis populations were analyzed based on chloroplast DNA (Salehi Shanjani et al. 2004). The distribution of the cpDNA haplotypes revealed a geographical structure, which may reflect migration history and suggested a center of haplotype diversity in the north western part of Iran, close to the Hyrcanian forests (Salehi Shanjani et al. 2004). Salehi Shanjani et al. (2011) studied genetic variation of $F$. orientalis populations along two altitudinal gradients in Iran based on nuclear simple sequence repeats (nSSRs) and isozymes. The authors found high levels of genetic diversity for $F$. orientalis populations, but no genetic structuring along altitudinal transects. Also the effect of geographical variation on morphological and anatomical leaf traits of 
Oriental beech was studied in different Iranian provinces. Significant variation in leaf traits was detected among the investigated natural populations likely as an effect of environmental adaptation or phenotypic plasticity (Bayramzadeh et al. 2012, Bijarpasi et al. 2019).

Here, we intend to extend the knowledge of genetic diversity and genetic structure of $F$. orientalis in the Hyrcanian forest by investigating three Oriental beech populations located in the Alborz Mountains in Iran. We selected populations, which are growing at different elevations to investigate potential altitudinal adaptation putatively reflected by the genetic structure of the populations. We put the genetic analysis in a wider context by comparing the Iranian populations to a F. orientalis and a Fagus sylvatica L. population from the hybrid zone of the two taxa in southeast Europe, and to a F. sylvatica population from central Europe. The genetic structure of the populations may give further insights into the taxonomic status (species/ subspecies) of F. orientalis and F. sylvatica, which still needs to be clarified (Renner et al. 2016, Gömöry et al. 2018). We take advantage of recently developed EST-SSR markers (Burger et al. 2018) which allowed to clearly differentiate between F. sylvatica and $F$. orientalis and to identify hybridization zones between both species (Müller et al. 2019). Especially one trinucleotide repeat marker revealed very high interspecific differentiation and might be involved in adaptive species differences (Müller et al. 2019).

Our specific objectives were to (i) assess the genetic diversity and structure of Iranian beech populations, (ii) to investigate the genetic differentiation between $F$. orientalis from Iran and $F$. orientalis from southeast Europe, and (iii) to analyze the genetic differentiation between $F$. orientalis and $F$. sylvatica.

\section{Materials and Methods}

\section{Plant material}

In total, 293 leaf samples were collected from three $F$. orientalis populations from northern Iran (Bolor, Sihahroud and Changool) (Fig. 1, Table 1). These populations were located at three different elevations (700 m a.s.l., $1200 \mathrm{~m}$ a.s.l. and $1700 \mathrm{~m}$ a.s.I.) in the Alborz Mountains in the Hyrcanian forest (Table 1). The selection of populations growing at different elevations may reveal insights into potential altitudinal adaptation putatively reflected by the genetic structure of the populations. The Bolor population is located in a mixed forest, in which Oriental beech is growing together with tree species such as Alnus subcordata C.A.Mey., Carpinus betulus L., and Acer velutinum Boiss., whereas the other two populations are pure F. orientalis stands. In each population, two transects were selected (labeled with "W" for "west" and "E" for "east" in the following) for the collection of leaf samples to cover a larger part of the populations growing along the altitudinal gradient. The distance between transects within populations was $200 \mathrm{~m}$. Within transects the average distance of sampled trees was kept to be approximately $50 \mathrm{~m}$. Further, microsatellite data of a F. orientalis population located in northwest Turkey (Demirkoy) and of two F. sylvatica populations, one from northwest Greece (Alevitsa) and one from Germany (Goehrde) were obtained from Müller et al. (2019) and scored consistently (Table 1).
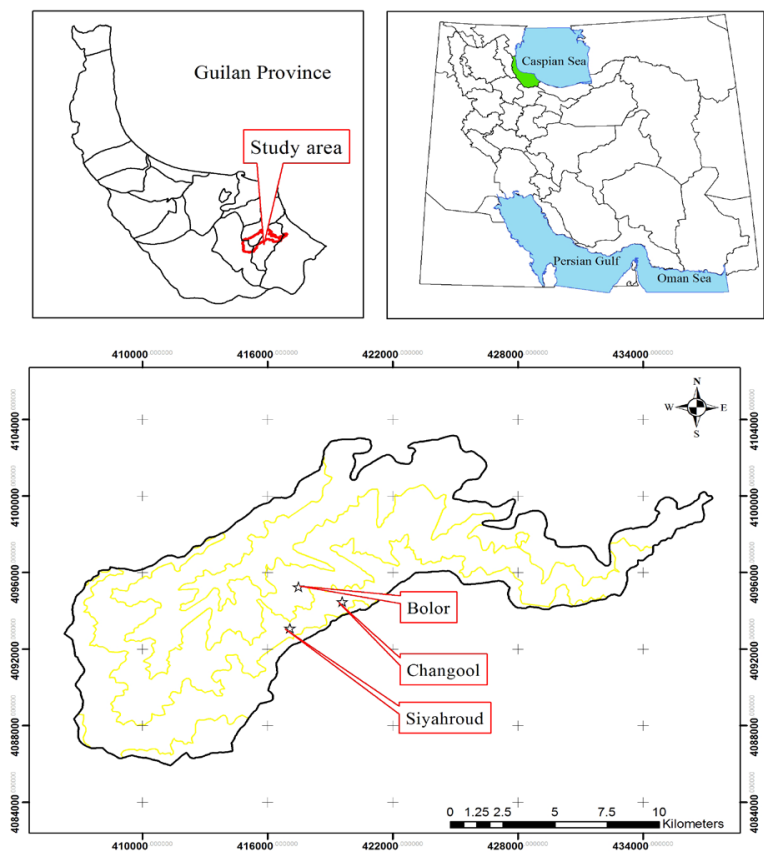

Figure 1

Location of the sampling sites in Iran

Table 1 Population characteristics

\begin{tabular}{llcllll}
\hline $\begin{array}{l}\text { Population } \\
\text { name }\end{array}$ & Name & $\begin{array}{l}\text { No. of } \\
\text { Samples }\end{array}$ & Subspecies & Latitude & Longitude & $\begin{array}{l}\text { Altitude } \\
\text { (m a.s.l) }\end{array}$ \\
\hline Bolor.W & Iran & 50 & F. orientalis & 37.001388 & 50.072777 & 700 \\
Bolor. E & Iran & 50 & F. orientalis & 36.995833 & 50.072777 & 700 \\
Siyahroud. W & Iran & 49 & F. orientalis & 36.993055 & 50.094166 & 1200 \\
Siyahroud. E & Iran & 50 & F. orientalis & 36.990277 & 50.089722 & 1200 \\
Changool. W & Iran & 48 & F. orientalis & 36.980555 & 50.068888 & 1700 \\
Changool. E & Iran & 46 & F. orientalis & 36.976944 & 50.072777 & 1700 \\
Demirkoy & Turkey & 24 & F. orientalis & 41.819996 & 27.662091 & 611 \\
Alevitsa & Greece & 24 & F. sylvatica & 40.432116 & 20.963033 & 1250 \\
Goehrde & Germany & 24 & F. sylvatica & 53.122983 & 10.820400 & 85 \\
\hline
\end{tabular}

\section{DNA extraction and genotyping}

Total genomic DNA was extracted from leaf tissue using the DNeasy96 Plant Kit (Qiagen, Hilden, Germany). A total of nine EST-SSR markers (Kubisiak et al. 2009, Burger et al. 2018), which were adapted for use in F. orientalis and F. sylvatica (Müller et al. 2019), were selected for genotyping. Four primers were compiled into multiplex 1 (FgSI0006, FgSI0024, FS_C1968, FS C2361) and four primers were compiled into multiplex 2 (FgSI0009, FS_C7377, FS_C6785, FS_C7797), while the primer FS_C4971 was analyzed in a separate PCR. The PCR mix was composed of: $1 \mu \mathrm{L}$ genomic DNA (ca. $0.6 \mathrm{ng} / \mu \mathrm{L}$ ), $1.5 \mu \mathrm{L} 10 \mathrm{x}$ reaction buffer $B$ (Solis BioDyne, Tartu, Estonia), $1.5 \mu \mathrm{L} \mathrm{MgCl}_{2}$ 
(25 mM), $1 \mu \mathrm{L}$ dNTPs (2.5 mM each dNTP), $0.2 \mu \mathrm{L}(5 \mathrm{U} / \mu \mathrm{L})$ HOT FIREPol Taq DNA polymerase (Solis BioDyne, Tartu, Estonia), 0.2 $\mu \mathrm{L}$ tailed (Schuelke 2000, Kubisiak et al. 2013) forward primer (5 $\mathrm{pM} / \mu \mathrm{L}$ ), $0.5 \mu \mathrm{L}$ PIG-tailed (Brownstein et al. 1996) reverse primer $(5 \mathrm{pM} / \mu \mathrm{L}), 1 \mu \mathrm{L}(5 \mathrm{pM} / \mu \mathrm{L})$ dye labeled (6-FAM or $6-\mathrm{HEX})$ M13 primer, and $\mathrm{H}_{2} \mathrm{O}$ (filled up to a volume of $12.4 \mu \mathrm{L}$ ). The PCR reaction was performed using a touchdown program. It consisted of an initial denaturation at $95^{\circ} \mathrm{C}$ for $15 \mathrm{~min}$, followed by 10 cycles of $94^{\circ} \mathrm{C}$ for $1 \mathrm{~min}, 1 \mathrm{~min}$ at $60^{\circ} \mathrm{C}$ (decreasing $1^{\circ} \mathrm{C}$ per cycle) and at $72{ }^{\circ} \mathrm{C}$ for $1 \mathrm{~min}$, followed by 25 cycles at $94^{\circ} \mathrm{C}$ for 1 $\min , 50^{\circ} \mathrm{C}$ for $1 \mathrm{~min}$ and $72^{\circ} \mathrm{C}$ for $1 \mathrm{~min}$, and a final extension step at $72{ }^{\circ} \mathrm{C}$ for $20 \mathrm{~min}$. The PCR products were separated using an $A B I 3130 x l$ Genetic Analyzer (Applied Biosystems, Foster City, CA, USA). Fragments were scored using GeneMapper 4.0 (Applied Biosystems, Foster City, CA, USA). Samples of a population from a previous study (Müller et al. 2019) were used as positive controls in the genotyping process to ensure a reliable scoring and binning of alleles.

\section{Data analysis}

\section{Genetic diversity of Iranian and European popula- tions}

Genetic variation in all populations was calculated as the number of alleles per locus $\left(N_{a}\right)$, observed heterozygosity $\left(H_{o}\right)$, expected heterozygosity $\left(H_{e}\right)$, and number of private alleles in the GenAIEx software version 6.503 (Peakall and Smouse 2006, Peakall and Smouse 2012). Inbreeding coefficients $\left(F_{15}\right)$ and their significance were determined using Genepop 4.7.2 (Rousset 2008). Allelic richness $\left(A_{R}\right)$ was calculated with the FSTAT 2.9.4. software (Goudet 1995). Differences in genetic diversity parameters for the analyzed populations (pairwise comparisons among all populations, Iranian and European populations, F. sylvatica and F. orientalis, and Iranian populations from different elevations) were tested using the Kruskal-Wallis test with multiple comparisons implemented in the $\mathrm{R}$ package pgirmess 1.6.7 (Giraudoux 2017).

\section{Population structure and genetic differentiation} The STRUCTURE 2.3.4 software (Pritchard et al. 2000) was used to infer population structure among all populations. The admixture model and correlated allele frequencies were used. The Markov chain Monte Carlo (MCMC) iterations included a burn-in period of 10,000 iterations followed by 100,000 iterations. Potential clusters $(\mathrm{K})$ from 1 to 15 were tested using 10 iterations. The $\Delta \mathrm{K}$ method (Evanno et al. 2005) was used to determine the most likely number of $\mathrm{K}$ with the STRUCTURE HARVESTER 0.6.94 program (Earl and vonHoldt 2012). The CLUMPAK software (Kopelman et al. 2015) was employed for summation and graphical representation of the STRUCTURE results. Pairwise $G_{S T}$ values between all populations based on 999 permutations and a principal coordinates analysis (PCoA) were performed with GenAlEx (Peakall and Smouse 2006, Peakall and Smouse 2012). A neighbor-joining (NJ) dendrogram based on Nei's genetic distance (Nei 1972) was generated using the populations 1.2.32 software (Langella 1999) and visualized using TreeView 1.6.6 (Page 1996). Bootstrap values were calculated based on 1000 permutations over loci.

\section{Outlier analyses}

Outlier analyses for the Iranian populations (Bolor, Sihahroud and Changool) as well as for a comparison of $F$. sylvatica and $F$. orientalis populations were performed with the BayeScan 2.1 software (Foll and Gaggiotti 2008) using default parameters. Loci with $q$-values lower than $5 \%$ were considered as outliers. Selected sequences that contained loci of interest (outlier loci or loci that showed a strong differentiation between European and Oriental beech populations) were annotated. For that, similarity searches against the beech genome (Mishra et al. 2018) were conducted for sequences that were used for the original EST-SSR marker design using MegaBLAST (Morgulis et al. 2008) implemented in the NCBI Genome Workbench 3.1.0 (https://www.ncbi.nlm.nih.gov/tools/gbench/). The searchable beech genome browser (http://thines-lab.senckenberg.de/ beechgenome/index3.html) was used to determine the location of the respective SSR locus within the beech genome.

\section{Results}

\section{Genetic diversity and differentiation among} Iranian populations

The mean number of alleles $\left(N_{a}\right)$ ranged from 4.2 for the Siyahroud W-Iran population to 5.3 for the Siyahroud E-Iran population (Table 2 ). The observed heterozygosity $\left(H_{o}\right)$ ranged from 0.317 for the Siyahroud W-Iran population to 0.409 for the Changool E-Iran population (mean $H_{o}: 0.376$ ), while the expected heterozygosity $\left(H_{e}\right)$ ranged from 0.334 for the Siyahroud W-Iran population to 0.396 for the Bolor W-Iran population (mean $H_{e}: 0.373$ ). Allelic richness $\left(A_{R}\right)$ ranged from 3.5 for the Siyahroud W-Iran population to 4.3 for the Bolor W-Iran population. No significant differences were found for the genetic diversity indices among populations or elevations. Total $F_{\text {is }}$ was 0.003 over all Iranian populations and $F_{\text {Is }}$ was not significantly different from zero in any population (Table 2). Over all loci the $G_{S T}$ value was 0.010 . No influence of elevation on genetic differentiation was observable (Table S1). 
Table 2

Sample size and mean genetic diversity indices for all populations

\begin{tabular}{lcccccc}
\hline Population & $N$ & $A_{R}$ & $N_{a}$ & $H_{o}$ & $H_{e}$ & $F_{I S}$ \\
\hline Fo-Bolor W-Iran & 49.8 & 4.3 & 5.0 & 0.397 & 0.396 & 0.006 \\
Fo-Bolor E-Iran & 50.0 & 4.1 & 5.0 & 0.376 & 0.389 & 0.044 \\
Fo-Siyahroud W-Iran & 49.0 & 3.5 & 4.2 & 0.317 & 0.334 & 0.059 \\
Fo-Siyahroud E-Iran & 49.8 & 4.2 & 5.3 & 0.378 & 0.372 & -0.007 \\
Fo-Changool W-Iran & 47.6 & 4.1 & 5.1 & 0.379 & 0.365 & -0.027 \\
Fo-Changool E-Iran & 44.9 & 4.1 & 5.0 & 0.409 & 0.383 & -0.056 \\
Mean & 48.5 & 4.1 & 4.9 & 0.376 & 0.373 & 0.003 \\
Fo-Demirkoy-Turkey & 23.6 & 5.0 & 5.2 & 0.569 & 0.521 & -0.067 \\
Fs-Alevista-Greece & 23.9 & 4.2 & 4.3 & 0.506 & 0.498 & 0.005 \\
Fs-Goehrde-Germany & 24.0 & 3.4 & 3.4 & 0.421 & 0.402 & -0.027 \\
Mean & 23.8 & 4.2 & 4.3 & 0.499 & 0.474 & -0.030 \\
Mean (all) & 40.3 & 4.1 & 4.7 & 0.417 & 0.406 & -0.008 \\
\hline
\end{tabular}

$N$ : number of individuals, $A_{R}$ : allelic richness, $N_{a}$ : number of alleles, $H_{0}$ : observed heterozygosity, $H_{e}$ : expected heterozygosity, $F_{I S}$ : inbreeding coefficient. Fo: Fagus orientalis, Fs: Fagus sylvatica

Comparison of genetic diversity, genetic differentiation, and genetic structure between Iranian and European populations

The genetic diversity indices were similar for all analyzed populations (Table 2). Only the comparison between Iranian and European populations revealed differences in $H_{o^{\prime}}$ albeit this result might be affected by sample size and species.

The mean number of alleles $\left(N_{a}\right)$ over all populations ranged from 2.3 for marker FgSI0006 to 11.2 for marker FS_C1968 (Table 3). The observed heterozygosity $\left(H_{0}\right)$ ranged from 0.166 for marker FgSI0006 to 0.830 for marker FS_C1968, and the expected heterozygosity $\left(\mathrm{H}_{e}\right)$ ranged from 0.158 for marker FgSI0006 to 0.830 for marker FS_C1968. None of the markers showed $F_{15}$ values significantly different from zero.
Marker FS_C6785 showed low $G_{S T}$ values among F. orientalis populations $(0.017)$, but high genetic differentiation between $F$. sylvatica and $F$. orientalis populations $\left(G_{S T}: 0.503\right)$ (Table 3). This marker showed distinct allele frequencies between Oriental and European beech populations in a previous study (Müller et al. 2019). In the present study, allele 189 was almost absent in the Iranian populations (only one individual showed the allele), whereas the previous study revealed frequencies of 0.042 in the Turkish F. orientalis population and a frequency of 0.792 and 0.938 in the Greek and German F. sylvatica populations, respectively (Fig. 2a). Allele 192 had a frequency of 0.784 in the Iranian populations, a frequency of 0.854 in the Turkish Oriental beech population, and a frequency of 0.208 and 0.063 in the Greek and German F. sylvatica populations, respectively (see also Müller et al. 2019). While only two alleles (189 and 192) were present at this marker in the European beech populations, additional alleles were found for Oriental beech (Fig. 2a).

Also marker FgSI0006 showed low differentiation among F. orientalis populations $\left(G_{S T}: 0.056\right)$, but high differentiation between $F$. sylvatica and F. orientalis populations $\left(G_{S T}: 0.319\right)$ (Table 3). The allele 261 at this marker is fixed in all but one Iranian populations, whereas it occurs in lower frequencies in the European beech populations that show a higher number of alleles (Fig. 2b).

Table 3

Mean genetic diversity indices over all populations for each marker and $G_{S T}$ values for different population comparisons

\begin{tabular}{|c|c|c|c|c|c|c|c|c|c|}
\hline Marker & $N$ & $N_{a}$ & $H_{0}$ & $H_{e}$ & $F_{\text {is }}$ & all populations & F. orientalis (Iran) & $\begin{array}{l}G_{S T} \\
\text { F. orientalis (all) }\end{array}$ & F. orientalis vs. F. sylvatica \\
\hline FgSI0006 & 40.6 & 2.3 & 0.166 & 0.158 & -0.020 & $0.425^{*}$ & 0.005 & $0.056^{*}$ & $0.319^{*}$ \\
\hline FgSI0024 & 40.3 & 6.0 & 0.691 & 0.671 & -0.019 & $0.038^{*}$ & $0.006^{*}$ & $0.016^{*}$ & $0.032^{*}$ \\
\hline FS_C1968 & 39.4 & 11.2 & 0.830 & 0.830 & 0.014 & $0.045^{*}$ & $0.007^{*}$ & $0.018^{*}$ & $0.040^{*}$ \\
\hline FS_C2361 & 40.6 & 3.9 & 0.356 & 0.364 & 0.044 & $0.146^{*}$ & 0.000 & 0.003 & $0.144^{*}$ \\
\hline FgSI0009 & 39.9 & 3.7 & 0.292 & 0.262 & -0.085 & $0.185^{*}$ & $0.024^{*}$ & $0.180^{*}$ & $0.008^{*}$ \\
\hline FS_C6785 & 40.4 & 3.1 & 0.333 & 0.312 & -0.040 & $0.402^{*}$ & 0.007 & $0.017^{*}$ & $0.503^{*}$ \\
\hline FS_C7377 & 40.2 & 2.6 & 0.283 & 0.264 & -0.044 & $0.205^{*}$ & 0.007 & $0.247^{*}$ & 0.000 \\
\hline FS_C7797 & 40.4 & 4.0 & 0.367 & 0.387 & 0.062 & $0.086^{*}$ & $0.034^{*}$ & $0.086^{*}$ & $0.018^{*}$ \\
\hline FS_4971 & 40.6 & 5.9 & 0.433 & 0.411 & -0.021 & $0.171^{*}$ & 0.004 & $0.216^{*}$ & $0.022^{*}$ \\
\hline Mean/total & 40.3 & 4.7 & 0.417 & 0.406 & -0.008 & $0.161^{*}$ & $0.010^{*}$ & $0.084^{*}$ & $0.132^{*}$ \\
\hline
\end{tabular}


a

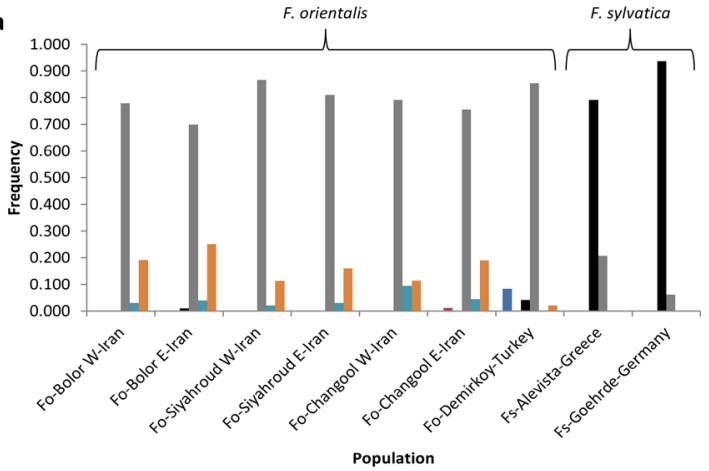

b

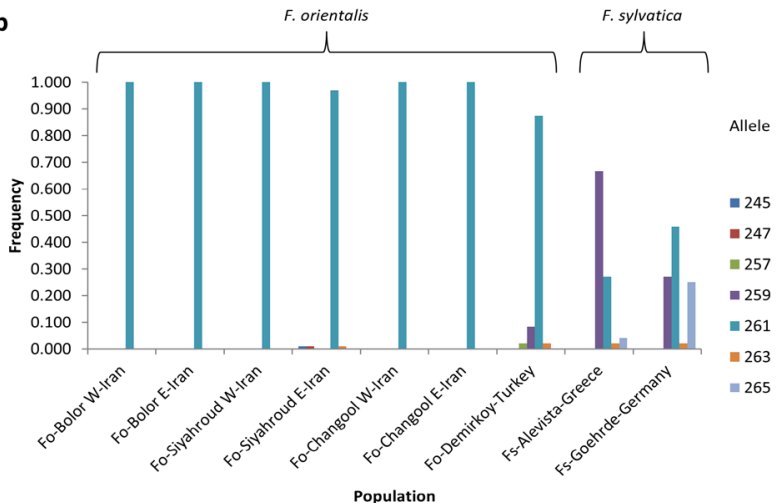

Figure 2

Allele frequencies at markers FS_C6785 (a) and FgSI0006 (b) for the different populations

Over all loci the $G_{S T}$ value was 0.161 among all populations, 0.010 for the Iranian populations, 0.084 among all F. orientalis populations (Iranian populations and the population Demirkoy from Turkey), and 0.132 between F. orientalis and F. sylvatica populations (Table 3). Pairwise $G_{S T}$ values among populations can be found in Table S1.

The results of the STRUCTURE analysis are shown in Figure 3. The $\Delta K$ method revealed a most likely number of two clusters $(K=2)$, while the In probability of the data $(L(k))$ indicated $\mathrm{K}=7$ as the most likely number of clusters (Figs. S1(a) and (b)). For $\mathrm{K}=2$, populations from Iran were clearly separated from populations from Turkey, Greece, and Germany (Fig. 3). For K = 7, the populations grouped into different clusters: the six populations from Iran formed an admixed group which is clearly distinct from the F. orientalis population from Turkey and the F. sylvatica populations from Greece and Germany (Fig. 3). A similar pattern was found in a NJ dendrogram (Fig. 4a), where the two F. sylvatica populations cluster together with high bootstrap support, and a PCoA based on individuals and populations (Figs. 4b and S2). In the PCoA F. orientalis individuals from Turkey occupy an intermediate position between $F$. sylvatica and F. orientalis from Iran (Fig. 4b).

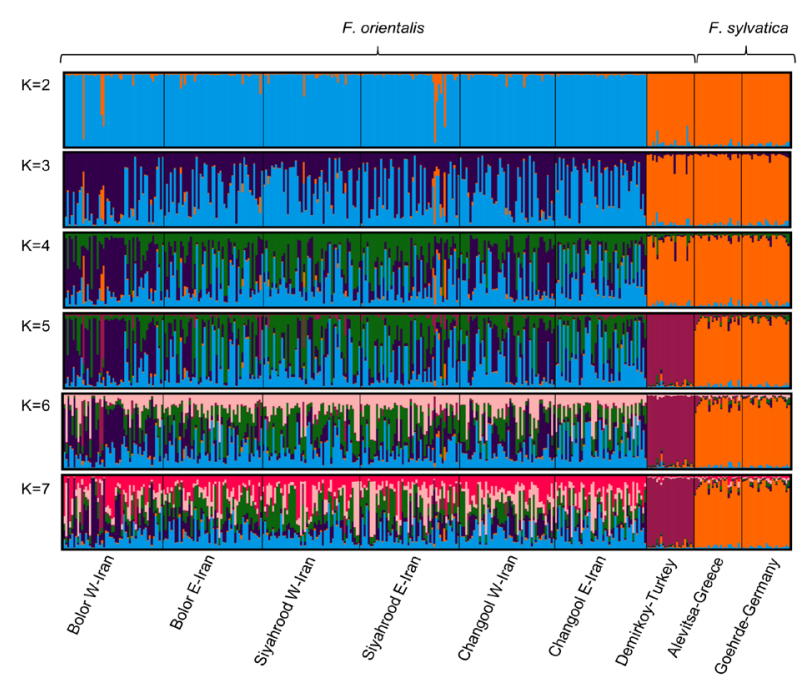

Figure 3

Clustering of individuals from $\mathrm{K}=2$ to $\mathrm{K}=7$

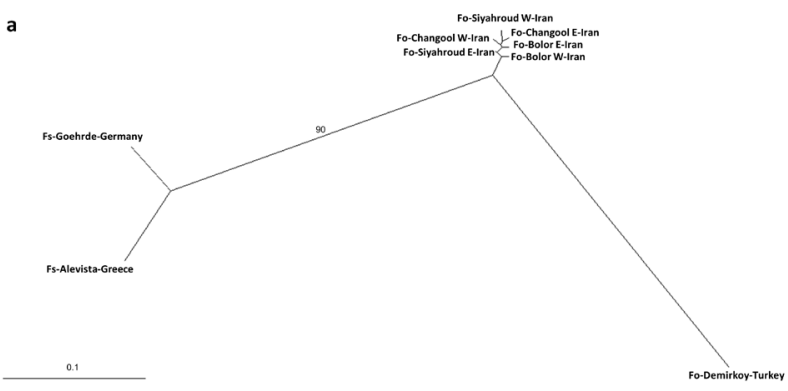

b

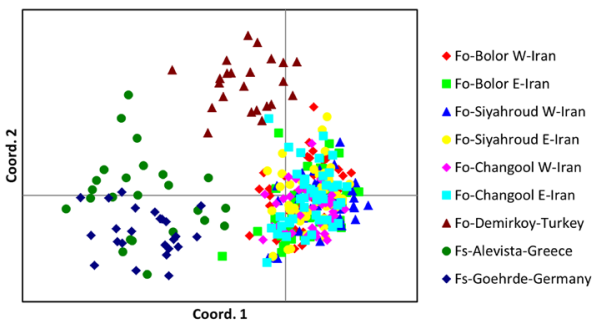

Figure 4

NJ dendrogram for all populations (bootstrap values $\geq 50$ are shown) (a) and principal coordinates analyses ( $P C O A$ ) for the different populations (b)

The outlier analysis revealed the marker FS_C1968 to be under balancing or purifying selection for both, outlier tests among the Iranian populations ( $q$-value $<0.01$, alpha coefficient: -1.8 ) as well as for the comparison of F. sylvatica and F. orientalis populations ( $q$-value $<0.0001$, alpha coefficient: -1.8 ) (Figs. S3(a) and (b)). 


\section{Discussion}

In this study, we investigated the genetic diversity and structure of Iranian Oriental beech populations at EST-SSR markers and compared the genetic structures with those of Oriental beech from Turkey as well as European beech populations from Greece and Germany.

\section{Genetic diversity}

For all analyzed beech populations high genetic diversity was revealed (mean $A_{R}: 4.1$ mean $H_{o}: 0.417$, mean $H_{e}$ : 0.406), which was similar to values previously reported for beech (Rajendra et al. 2014, Dounavi et al. 2016, Burger et al. 2018). No significant differences in genetic diversity indices were revealed for pairwise comparisons among all populations, Iranian and European populations, F. sylvatica and F. orientalis populations, or Iranian populations from different elevations. Only a comparison between Iranian and European populations revealed a significantly higher observed heterozygosity for the European populations. Nevertheless, since the European populations also included $F$. sylvatica and the number of populations in each group was different, the trend of higher $H_{o}$ in European populations needs to be confirmed in future studies. Furthermore, no $F_{\text {Is }}$ values significantly different from zero were observed. Thus, the populations show a high genetic diversity without signs of inbreeding. The results are in agreement with the results of our previous study (Müller et al. 2019), in which we investigated the genetic diversity and structure of European $F$. orientalis and F. sylvatica populations based on the same marker set, albeit slightly higher genetic diversity was detected compared to the Iranian populations investigated in the present study.

Genetic differentiation among Iranian populations Low genetic differentiation was found among the Iranian populations $\left(G_{S T}: 0.010\right)$, and hence, no effect of elevation on the genetic differentiation of the populations was detected. This is in agreement with Salehi Shanjani et al. (2011), who also found low genetic differentiation among $F$. orientalis populations at different elevations in Iran. The outlier analysis among Iranian populations revealed one marker (FS_C1968) to be under balancing or purifying selection. This marker was annotated as being located in a putative auxin-response protein in a previous study (Burger et al. 2018). The search against the beech genome (Mishra et al. 2018) in the present study also showed that this locus is located in a gene annotated as auxinresponsive IAA16-like. Auxin-response factors can be involved in abiotic adaptation in trees (Derory et al. 2006, Homolka et al. 2013, Modesto et al. 2014, Müller and Gailing 2019). Like in a previous study (Müller et al. 2019), marker FS_C1968 was also revealed as an outlier locus with signatures of balancing or purifying selection between European and Oriental beech populations. The SSR motif of the marker, however, is located in the non-coding region of the gene in the beech genome, and hence, likely not directly involved in adaptation, but putatively linked to genetic regions under selection. Despite the potential adaptive character of the markers used (EST-SSRs), future studies may apply adaptive markers such as SNPs within candidate genes for environmental adaptation (e.g., Müller and Gailing 2019) to investigate potential signs of selection in more detail.

\section{Genetic differentiation between F. sylvatica and $F$. orientalis}

The taxonomic status of F. orientalis and Fagus sylvatica L. still needs to be clarified (Renner et al. 2016, Gömöry et al. 2018) and previous studies indicated hybridization between the two taxa in the species' contact zone in the Rodopi Mountains in northeastern Greece (Hatziskakis et al. 2011, Müller et al. 2019). Therefore, we also included European F. orientalis and F. sylvatica populations in the analysis.

High genetic differentiation was found between the Iranian populations and the Turkish F. orientalis population (mean $\left.G_{s T}: 0.131\right)$ as well as between Iranian populations and a German and Greek F. sylvatica population (mean $G_{S T}: 0.162$ and 0.150 , respectively). This genetic differentiation pattern was also detected by STRUCTURE and PCoA analyses and in a NJ dendrogram, which separated the Iranian populations from the Turkish F. orientalis population and the two F. sylvatica populations. Thus, there are not only distinct genetic differences between $F$. orientalis and $F$. sylvatica populations, but also between Iranian and Turkish F. orientalis populations. These differentiation patterns are not observed evenly across all markers, but rather for single markers such as FgSI0009, FS_C7377, and FS 4971 for the European F. orientalis population and the Iranian populations or markers FgSI0006 and FS_C6785 for the differentiation between European and Oriental beech (Table 2). Also, Müller et al. (2019) found that the EST-SSR marker FS C6785 showed specific allele frequencies for $F$. orientalis and $F$. sylvatica and may be used as a diagnostic marker to differentiate both taxa. Therefore, we analyzed the allele frequencies of the species-specific alleles in the Iranian populations and compared them with the previous results. Allele 189, previously found to show high frequencies in F. sylvatica but low frequencies in F. orientalis, was almost absent (it occurred in only one individual) in the Iranian populations (Fig. 2). Allele 192, that previously showed high frequencies in Oriental beech, had also a high frequency in the Iranian populations (0.784). Thus, especially the almost complete absence of allele 189 may be characteristic for "pure" F. orientalis populations that are not coming into contact with F. sylvatica. The high differentiation between taxa at this marker may be the result of divergent selection. Outlier tests with additional markers as neutral reference should be performed for statistical validation. The two alleles 189 and 192 were the only alleles at this marker for the European beech populations, whereas additional alleles were found for Oriental beech (Fig. 2). Albeit these alleles (e.g. alleles 195 and 198) were not specific for the Iranian populations, they occurred in higher frequencies compared to Oriental beech from Greece and Turkey (Müller et al. 2019). The marker FS_ C6785 was previously annotated as being located in a sequence coding a putative ribosomal protein based on BLAST searches against the UniProt Viridiplantae database (The UniProt 
Consortium 2017, Burger et al. 2018). The annotation based on the beech reference genome (Mishra et al. 2018) in the present study revealed that the trinucleotide repeat of the marker is located in the coding region of a gene annotated as macrophage erythroblast attacher. The function of this gene, that is named for its role in animal systems, is difficult to determine for plant species (Holt 2011). The different annotations in the two studies shows the difficulty of gene annotation in non-model tree species. Nevertheless, the location of the marker within the coding region of a gene, suggests that it can be involved in adaptive genetic differentiation between the European and Oriental beech. Also for a second marker (FgSI0006) low differentiation among $F$. orientalis populations $\left(G_{S T}: 0.056\right)$, but high differentiation between $F$. sylvatica and $F$. orientalis populations $\left(G_{S T}: 0.319\right)$ was found (Table 2). While the allele 261 at this marker is fixed in all but one Iranian populations, it occurs in lower frequencies in the European beech populations (Fig. 3). The European populations, however, show a higher number of alleles at this marker. The trinucleotide repeat motif of locus FgSI0006 is also located in the coding region of a gene within the beech genome annotated as cold-regulated 413 inner membrane chloroplastic-like isoform X1. A similar gene annotation was found in the previous study (cold regulating 314 thylacoid membrane) (Burger et al. 2018). Thus, this gene may be involved in cold acclimation.

\section{Conclusions}

We found a high genetic diversity for all analyzed beech populations, but low genetic differentiation among Iranian Oriental beech populations growing at different altitudes suggesting effective gene flow among populations. In contrast, high genetic differentiation was found between the Iranian populations and the analyzed European populations (F. orientalis and F. sylvatica). Future studies may investigate Oriental beech populations growing between the sampled Turkish Oriental beech population and the Iranian populations to analyze whether there is a gradient of genetic differentiation of Oriental beech along its distribution range from Eastern Europe to Iran. One genetic marker (FS_C6785) was confirmed to be a useful marker to discriminate $F$. sylvatica and F. orientalis populations.

\section{Acknowledgements}

Mahboobeh Mohebi Bijarpasi was supported by a scholarship from the Iranian Ministry of Science, Research and Technology. We thank Mrs. Christine Radler for her help with the lab work.

\section{References}

Ahmadi MT, Attarod P, Mohadjer MRM, Rahmani R, Fathi J (2009) Partitioning rainfall into throughfall, stemflow, and interception loss in an oriental beech (Fagus orientalis Lipsky) forest during the growing season. Turkish Journal of Agriculture and Forestry 33(6):557-568. doi: 10.3906/tar-0902-3
Bayramzadeh V, Attarod P, Ahmadi MT, Ghadiri M, Akbari R, Safarkar T, Shirvany A (2012) Variation of leaf morphological traits in natural populations of Fagus orientalis Lipsky in the Caspian forests of Northern Iran. Annals of Forest Research 55(1):33-42. doi: 10.15287/afr.2012.73

Bijarpasi MM, Shahraji TR, Lahiji HS (2019) Genetic variability and heritability of some morphological and physiological traits in Fagus orientalis Lipsky along an elevation gradient in Hyrcanian forests. Folia Oecologica 46(1):4553. https://doi.org/10.2478/foecol-2019-0007

Brownstein MJ, Carpten JD, Smith JR (1996) Modulation of non-templated nucleotide addition by Taq DNA polymerase: primer modifications that facilitate genotyping. Biotechniques 20(6):1004-1006, 1008-1010. https://doi.org/10.2144/96206st01

Burger K, Müller M, Gailing O (2018) Characterization of EST-SSRs for European beech (Fagus sylvatica L.) and their transferability to Fagus orientalis Lipsky, Castanea dentata Bork., and Quercus rubra L. Silvae Genetica 67(1):127-132. https://doi.org/10.2478/sq-2018-0019

Derory J, Leger P, Garcia V, Schaeffer J, Hauser MT, Salin F, Luschnig C, Plomion C, Glossl J, Kremer A (2006) Transcriptome analysis of bud burst in sessile oak (Quercus petraea). New Phytologist 170(4):723-738. https://doi.org/10.1111/j.1469-8137.2006.01721.x

Dounavi A, Netzer F, Celepirovic N, Ivanković M, Burger J, Figueroa AG, Schön S, Simon J, Cremer E, Fussi B, Konnert M, Rennenberg H (2016) Genetic and physiological differences of European beech provenances (F. sylvatica L.) exposed to drought stress. Forest Ecology and Management 361:226-236. https://doi.org/10.1016/j.foreco.2015.11.014

Earl DA, vonHoldt BM (2012) STRUCTURE HARVESTER: a website and program for visualizing STRUCTURE output and implementing the Evanno method. Conservation Genetics Resources 4(2):359-361. https://doi.org/10.1007/s12686-011-9548-7

Evanno G, Regnaut S, Goudet J (2005) Detecting the number of clusters of individuals using the software STRUCTURE: a simulation study. Molecular Ecology 14(8):2611-2620. https://doi.org/10.1111/j.1365-294x.2005.02553.x

Foll M, Gaggiotti O (2008) A genome-scan method to identify selected loci appropriate for both dominant and codominant markers: a Bayesian perspective. Genetics 180(2):977-993. https://doi.org/10.1534/genetics.108.092221

Giraudoux P (2017) pgirmess: data analysis in ecology. R package version 1.6.7. [online]. To be found in <https://CRAN.R-project.org/package=pgirmess $>$

Gömöry D, Paule L, Mačejovský V (2018) Phylogeny of beech in western Eurasia as inferred by approximate Bayesian computation. Acta Societatis Botanicorum Poloniae 87(2):3582. https://doi.org/10.5586/asbp.3582

Goudet J (1995) FSTAT (Version 1.2): a computer program to calculate F-statistics. Journal of Heredity 86(6):485-486

https://doi.org/10.1093/oxfordjournals.jhered.a111627

Hatziskakis S, Tsiripidis I, Papageorgiou AC (2011) Leaf morphological variation in beech (Fagus sylvatica L.) populations in Greece and its relation to their post-glacial origin. Botanical Journal of the Linnean Society 165(4):422-436. https://doi.org/10.1111/j.1095-8339.2011.01124.x

Holt SH (2011) Genetic studies of phenotypic variants in the woodland strawberry, (Fragaria vesca). Blacksburg, USA: Virginia Polytechnic Institute and State University, $117 \mathrm{p}$

Homolka A, Schueler S, Burg K, Fluch S, Kremer A (2013) Insights into drought adaptation of two European oak species revealed by nucleotide diversity of candidate genes. Tree Genetics \& Genomes 9(5):1179-1192.

https://doi.org/10.1007/s11295-013-0627-7

Kopelman NM, Mayzel J, Jakobsson M, Rosenberg NA, Mayrose I (2015) CLUMPAK: a program for identifying clustering modes and packaging population structure inferences across K. Molecular Ecology Resources 15(5):11791191. https://doi.org/10.1111/1755-0998.12387

Kubisiak T, Carey D, Burdine C, Koch J (2009) Characterization of ten EST-based polymorphic SSR loci isolated from American beech, Fagus grandifolia Ehrh. Permanent genetic resources note added to Molecular Ecology Resources. Molecular Ecology Resources 9(6):1460-1466. doi: 10.1111/j.1755-0998.2009.02759.x

Kubisiak TL, Nelson CD, Staton ME, Zhebentyayeva T, Smith C, Olukolu BA, Fang GC, Hebard FV, Anagnostakis S, Wheeler N, Sisco PH, Abbott AG, Sederoff RR (2013) A transcriptome-based genetic map of Chinese chestnut (Castanea mollissima) and identification of regions of segmental homology with peach (Prunus persica). Tree Genetics \& Genomes 9(2):557-571. https://doi.org/10.1007/s11295-012-0579-3 
Langella O (1999) Populations version 1.2.32 [online]. To be found in $<$ http://www.bioinformatics.org/project/?group id=84>

Mishra B, Gupta DK, Pfenninger M, Hickler T, Langer E, Nam B, Paule J, Sharma R, Ulaszewski B, Warmbier J, Burczyk J, Thines M (2018) A reference genome of the European beech (Fagus sylvatica L.). Gigascience 7(6):giy063. https://doi.org/10.1093/gigascience/giy063

Modesto IS, Miguel C, Pina-Martins F, Glushkova M, Veloso M, Paulo OS, Batista D (2014) Identifying signatures of natural selection in cork oak (Quercus suber L.) genes through SNP analysis. Tree Genetics \& Genomes 10(6):1645-1660. https://doi.org/10.1007/s11295-014-0786-1

Morgulis A, Coulouris G, Raytselis Y, Madden TL, Agarwala R, Schäffer AA (2008) Database indexing for production MegaBLAST searches. Bioinformatics 24(16):1757-1764. https://doi.org/10.1093/bioinformatics/btn322

Müller M, Gailing O (2019) Abiotic genetic adaptation in the Fagaceae. Plant Biology 21(5):783-795.https://doi.org/10.1111/plb.13008

Müller M, Lopez PA, Papageorgiou AC, Tsiripidis I, Gailing O (2019) Indications of genetic admixture in the transition zone between Fagus sylvatica L. and Fagus sylvatica ssp. orientalis Greut. \& Burd. Diversity 11(6):90. https://doi.org/10.3390/d11060090

Nei M (1972) Genetic distance between populations. The American Naturalist 106(949):283-292. https://doi.org/10.1086/282771

Page RD (1996) TreeView: an application to display phylogenetic trees on personal computers. Computer Applications in the Biosciences 12(4):357-358. https://doi.org/10.1093/bioinformatics/12.4.357

Peakall R, Smouse PE (2006) genalex 6: genetic analysis in Excel. Population genetic software for teaching and research. Molecular Ecology Notes 6(1):288295. https://doi.org/10.1111/j.1471-8286.2005.01155.x

Peakall R, Smouse PE (2012) GenAIEx 6.5: genetic analysis in Excel. Population genetic software for teaching and research - an update. Bioinformatics 28(19):2537-2539. https://doi.org/10.1093/bioinformatics/bts460

Pritchard JK, Stephens M, Donnelly P (2000) Inference of population structure using multilocus genotype data. Genetics 155(2):945-959.

Rajendra KC, Seifert S, Prinz K, Gailing O, Finkeldey R (2014) Subtle human impacts on neutral genetic diversity and spatial patterns of genetic variation in European beech (Fagus sylvatica). Forest Ecology and Management 319:138-149. https://doi.org/10.1016/j.foreco.2014.02.003

Renner SS, Grimm GW, Kapli P, Denk T (2016) Species relationships and divergence times in beeches: new insights from the inclusion of 53 young and old fossils in a birth-death clock model. Philosophical Transactions of the Royal Society B 371(1699):20150135. https://doi.org/10.1098/rstb.2015.0135

Rousset F (2008) genepop'007: a complete re-implementation of the genepop software for Windows and Linux. Mol Ecol Resour 8(1):103-106. doi: 10.1111/j.1471-8286.2007.01931.x

Salehi Shanjani P, Paule L, Khavari-Nejad R, Gömöry D, Sagheb Talebi K (2002) Genetic diversity of Oriental beech (Fagus orientalis Lipsky) forests over the Hyrcanian zone. Forest Genetics 9(4):297-308.

Salehi Shanjani P, Vettori C, Giannini R, Khavari-Nejad RA (2004) Intraspecific variation and geographic patterns of Fagus orientalis Lipsky chloroplast DNA. Silvae Genetica 53(5-6):193-197. https://doi.org/10.1515/sg-2004-0035

Salehi Shanjani P, Vendramin GG, Calagari M (2010) Genetic diversity and differentiation of Fagus orientalis Lipsky in Hyrcanian forests revealed by nuclear and chloroplast microsatellite markers. Conservation Genetics 11(6):23212331. https://doi.org/10.1007/s10592-010-0118-4

Salehi Shanjani P, Vendramin GG, Calagari M (2011) Altitudinal genetic variations among the Fagus orientalis Lipsky populations in Iran. Iranian Journal of Biotechnology 9(1):11-20.

Schuelke M (2000) An economic method for the fluorescent labeling of PCR fragments. Nature Biotechnology 18(2):233-234. https://doi.org/10.1038/72708

The UniProt Consortium (2017) UniProt: the universal protein knowledgebase. Nucleid Acids Research 45:158-169. https://doi.org/10.1093/nar/gkw1099 